\title{
Kajian Karakteristik Visual Pakaian Tokoh Pada Perancangan Buku Cerita Bergambar Sejarah Perjuangan Sultan Ageng Tirtayasa
}

\author{
Ahmad Fuad $^{1}$, Putri Anggraeni Widyastuti ${ }^{2}$ \\ ${ }^{1}$ Program Studi Desain Komunikasi Visual, Fakultas Desain dan Industri Kreatif, Universitas Esa Unggul \\ Jakarta Barat, Jakarta 11510, Indonesia \\ ${ }^{2}$ Program Studi Desain Produk, Fakultas Desain dan Industri Kreatif, Universitas Esa Unggul \\ Jakarta Barat, Jakarta 11510, Indonesia \\ Email korespondensi: ahmad.fuad@esaunggul.ac.id
}

Received 5 March 2021, Revised 19 March 2021, Accepted 10 May 2021

\begin{abstract}
A picture storybook with a historical theme is a medium for conveying historical knowledge of a character in a certain era. One of the figures used in the design of a picture book with a historical theme is the history of the struggle of Sultan Ageng Tirtayasa. The history of the struggle of Sultan Ageng Tirtayasa, a hero figure who was known to be persistent in fighting against the Dutch colonialists. Sultan Ageng Tirtayasa's struggle against the Dutch in Serang, Banten earned him the title of National Hero by the Indonesian government. However, it is necessary to have a visual study of the characteristics of character clothing in the design of the picture book of Sultan Ageng Tirtayasa's struggle to understand the illustration of the clothes worn by the characters in the design of the picture book to present a historical atmosphere of the figure of Sultan Ageng Tirtayasa. In conclusion, through a visual analysis of the characteristics of the clothes of the characters in this picture book, a mimesis metaphor is used to trace the history of Sultan Agung Tirtayasa, to present a historical atmosphere is also adapted to the target market for users of this picture book.

Keywords: historical picture book, character clothing, the struggle of Sultan Ageng Tirtayasa,
\end{abstract} visual characteristics

\begin{abstract}
Abstrak - Buku cerita bergambar dengan tema sejarah adalah sebuah media penyampaian pengetahuan bertema sejarah sebuah tokoh dalam era tertentu. Salah satu tokoh yang dijadikan dalam perancangan buku cerita bergambar dengan tema sejarah adalah sejarah perjuangan Sultan Ageng Tirtayasa. Sejarah perjuangan Sultan Ageng Tirtayasa yang merupakan tokoh pahlawan yang dikenal gigih melakukan perlawanan terhadap penjajah Belanda. Perjuangan Sultan Ageng Tirtayasa melawan Belanda di Serang, Banten membuat beliau diberi gelar Pahlawan Nasional oleh pemerintah Indonesia. Namun demikian, diperlukan sebuah kajian visual karakteristik pakaian karakter pada perancangan buku bergambar perjuangan Sultan Ageng Tirtayasa agar memahami ilustrasi pakaian yang dikenakan karakter dalam perancangan buku bergambar tersebut dapat menghadirkan suasana sejarah tokoh Sultan Ageng Tirtayasa. Kesimpulannya, melalui analisa visual karakteristik pakaian tokoh dalam buku bergambar ini digunakan perancangan kombinasi metafora mimesis dan stilasi dengan penelusuran sejarah Sultan Agung Tirtayasa, agar dapat menghadirkan suasana sejarah yang juga disesuaikan dengan target market pengguna buku cerita bergambar ini
\end{abstract}

Kata Kunci: buku cerita bergambar sejarah, pakaian tokoh sejarah, Sultan Ageng Tirtayasa, karakteristik visual

\section{PENDAHULUAN}

Perancangan buku ilustrasi cerita rakyat dari Banten "Sultan Agung Tirtayasa" karya Juan Ef Reyza ini merupakan objek penelitian yang akan diangkat dalam penelitian ini. Perancangan buku ilustrasi cerita rakyat ini merupakan bagian dari buku cerita bergambar sejarah perjuangan tokoh. Sultan Ageng Tirtayasa bukan hanya sekedar tokoh dalam cerita rakyat Banten semata, tapi juga merupakan tokoh Banten yang berjuang melawan kolonial pada masanya. Perancangan buku ilustrasi yang memiliki bahasa bilingual ini, diperuntukkan bagi target pasar anak sekarang yang tidak hanya mengenal atau mempelajari Bahasa Indonesia tapi juga bahasa asing, Bahasa Inggris. Tujuan pembuatan ini selain untuk menanamkan sikap patriotisme dan pesan moral dari sejarah perjuangan Sultan Ageng Tirtayasa ini, juga untuk meningkatkan pengetahuan melalui bahasa asing, Bahasa Inggris. 


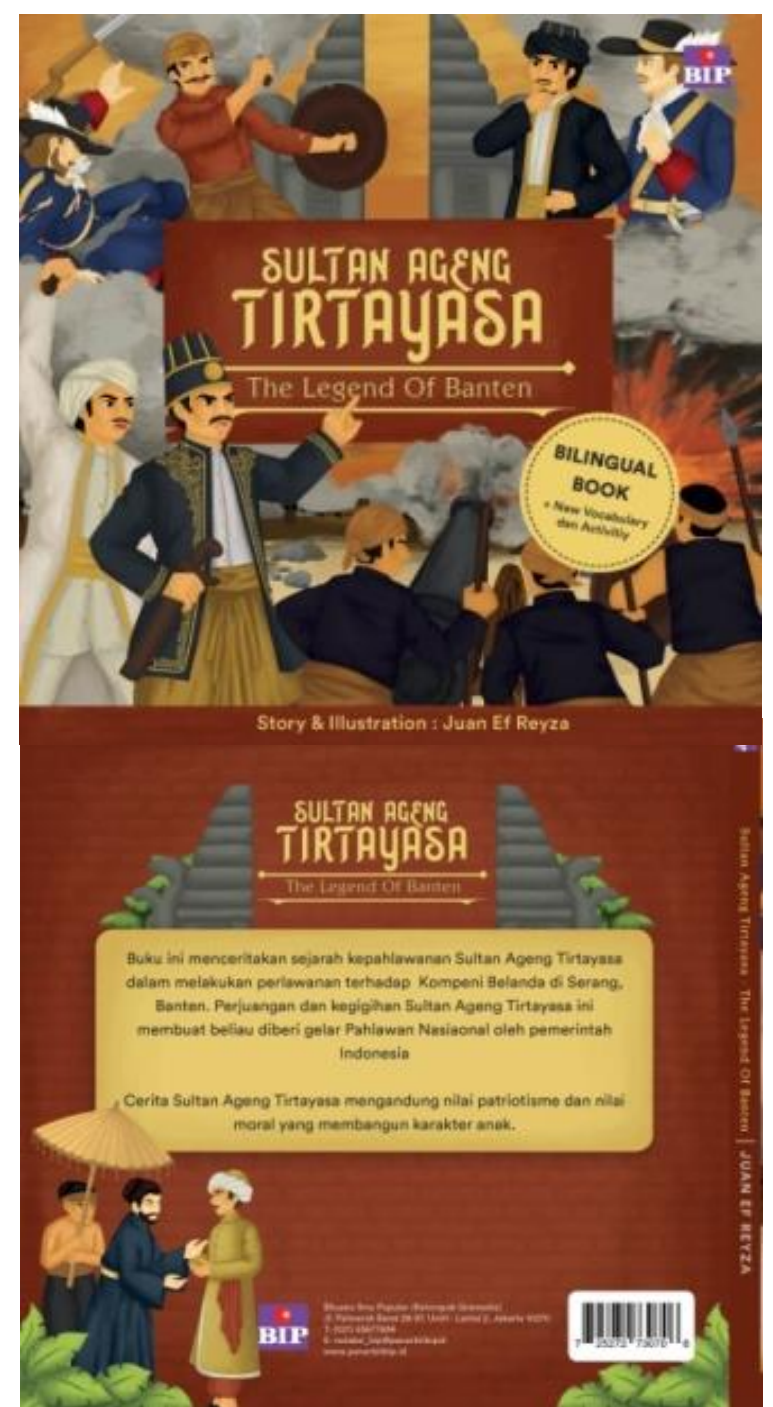

Gambar 1. Buku Cerita Bergambar Sejarah perjuangan "Sultan Ageng Tirtayasa" karya Juan Ef Reyza

Banten sebagai salah satu daerah di Pulau Jawa ini memiliki segudang cerita sejarah yang tak banyak orang mengetahuinya. Claude Guillot dalam buku, Banten; Sejarah dan peradaban abad X-XVII, seorang sejarawan dan arkeolog asal Prancis, mengatakan bahwa, “... Banten adalah negeri yang kaya sekali akan sumber-sumber sejarah. Kerajaan ini bukan hanya telah menulis sejarahnya sendiri, melainkan juga merangsang banyak tulisan dari pengunjung-pengunjung asing, khususnya Eropa...". Salah satu sejarah yang terkenal di Banten sendiri adalah mengenai perjuangan Sultan Ageng Tirtayasa. Beliau adalah Sultan Banten ke-6. Sultan Ageng Tirtayasa berkuasa di Kasultanan Banten pada periode 1651 - 1683. Ia memimpin banyak perlawanan terhadap VOC (Vereenigde Oostindische Compagnie) atau dalam bahasa Inggris disebut Dutch East India Company. Selama masa penjajahannya, VOC menerapkan perjanjian monopoli perdagangan yang merugikan Kasultanan Banten. Kemudian Sultan Ageng Tirtayasa menolak perjanjian ini dan menjadikan Banten sebagai
Pelabuhan terbuka. Saat itu, Sultan Ageng Tirtayasa ingin mewujudkan kerajaan Islam terbesar. Di bawah kepemimpinan Sultan Ageng Tirtayasa yang gagah berani dalam lakukan pertahanan dan perlawanan terhadap VOC inilah menjadikan dirinya dianugerahi gelar Pahlawan Nasional pada 1 Agustus 1970.

Penelitian ini ingin membahas bagaimana mengkaji karakteristik secara visual pakaian tokoh pada perancangan buku cerita bergambar sejarah perjuangan Sultan Ageng Tirtayasa? Tujuan dan manfaat penelitian ini adalah membedah dengan menganalisa visual karakteristik pakaian tokoh pada perancangan buku cerita bergambar sejarah perjuangan Sultan Ageng Tirtayasa agar dapat mengetahui apakah buku ini telah menghadirkan suasana sejarah perjuangan Sultan Ageng Tirtayasa dalam bentuk dua dimensi yang cocok untuk target pasarnya. Maka dari itu akan diperlukan beberapa pendapat untuk mendukung penelitian ini seperti perihal jenis pakaian yang dikenakan oleh tokohtokoh dalam perancangan buku cerita bergambar sejarah perjuangan Sultan Ageng Tirtayasa.

Sultan Ageng Tirtayasa yang telah berkuasa pada periode 1651-1683 ini, telah melakukan banyak hal dalam melawan penjajahan VOC di tanah Banten. Salah satunya beliau mengembangkan sumber daya pertanian di kerajaan Banten kala itu. Dari tahun 1663 - 1677, ia membangun sistem irigasi besarbesaran di Banten dengan adanya pembangunan kanal-kanal sepanjang 30-40 km dan mempekerjakan 16.000 dalam satu kesempatan. Dengan kesuksesan Sultan Ageng mengembangkan Banten dengan baik ini menjadikan dirinya sebagai salah satu musuh VOC yang tangguh. Pihak VOC ingin mendapatkan hak monopoli atas penyediaan lada yang ada di Banten dan mereka cemas karena Kesultanan Banten ini letaknya tidak jauh dari markas VOC di Batavia, kira-kira 75 kilometer di sebelah timur. Begitu Sultan Ageng Tirtayasa naik takhta di tahun 1651, konflik Banten - VOC pun muncul lagi. Hal ini terlihat dari tahun 1656 meletuslah perang, di mana pihak Banten menyerang daerah-daerah Batavia dan kapal-kapal VOC, sedangkan VOC memblokade Pelabuhan. Barulah di tahun 1659, tercapailah sebuah penyelesaian damai di antara keduanya. Selama masa periode berkuasa inilah, telah terjadi peperangan antara Banten dengan VOC. Bulan Maret 1682, pasukan VOC yang dipimpin oleh Franscois Tack dan Issac de Saint-Martin, berlayar menuju Banten. VOC mengusir orang-orang Eropa yang berdagang di Banten; orang-orang Inggris mengundurkan diri ke Bengkulu. Artileri Belanda pun memaksa keluar Sultan Ageng Tirtayasa dari tempat kediamannya setelah dikejar-kejar sampai ke daerah pegunungan hingga di bulan Maret 1683 pun akhirnya dia menyerah. Untuk beberapa lama setelah penangkapannya Sultan Ageng ditahan di Banten, dan kemudian dipindahkan ke Batavia, tempat ia wafat tahun 1695 (M.C. Ricklefs, 2008:184). 


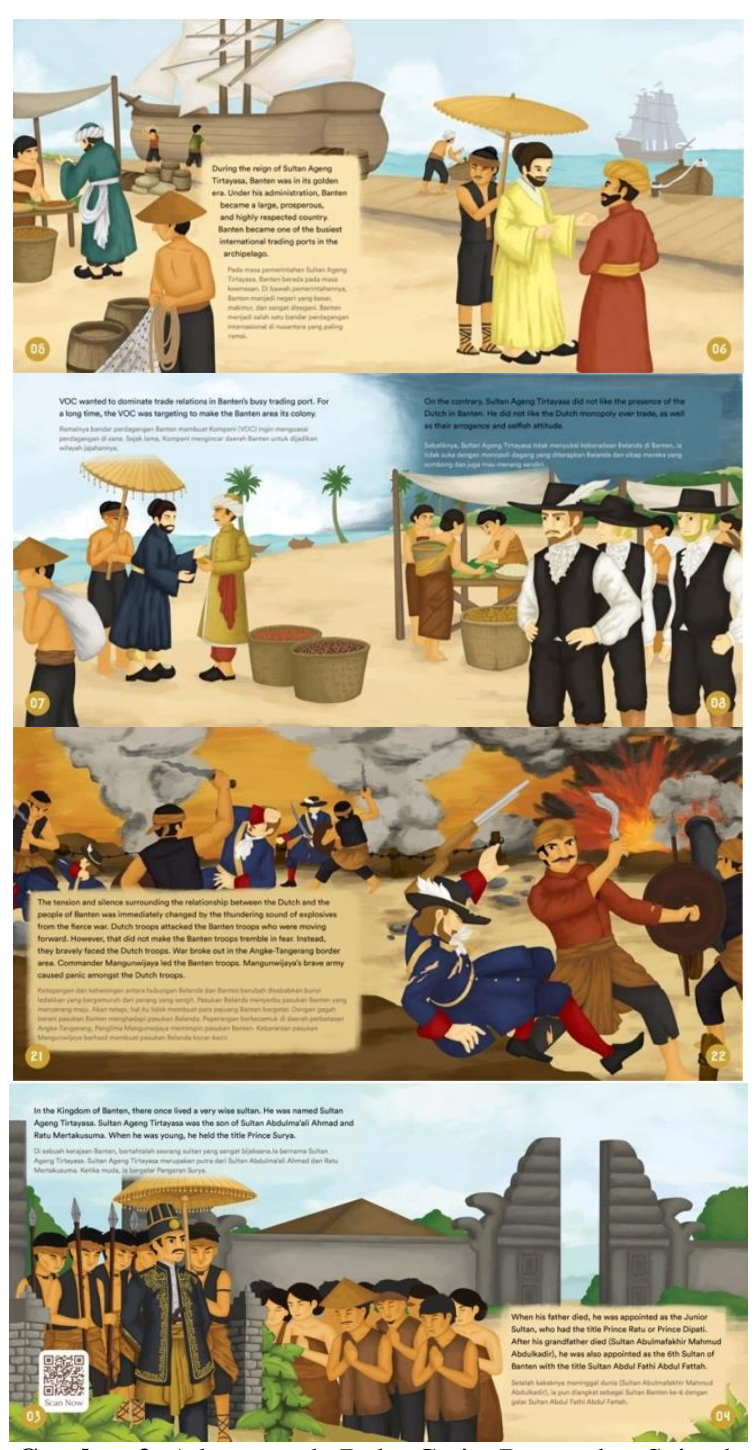

Gambar 2. Adegan pada Buku Cerita Bergambar Sejarah Perjuangan Sultan Ageng Tirtayasa

Dari hasil cerita singkat mengenai sejarah perjuangan Sultan Ageng Tirtayasa ini maka selanjutnya perihal pendukung penelitian ini adalah pakaian yang dikenakan dalam cerita Sultan Ageng Tirtayasa. Seperti yang diketahui keberadaan VOC pun tidak hanya berdampak buruk bagi Indonesia, tapi juga memiliki dampak baik yakni adanya perkembangan tekstil maupun pakaian yang dikenakan oleh masyarakat Indonesia. Begitu pula dengan perkembangan tekstil dan pakaian yang dikenakan masyarakat Kerajaan Banten, pihak Sultan Ageng Tirtayasa, dan juga para tentara VOC. Thomas Stamford Raffles dalam bukunya The History of Java menjelaskan bahwa penduduk asli Jawa di era itu berpakaian lebih baik dibandingkan penduduk di India Barat. Di banyak provinsi yang terletak di dataran tinggi atau daerah pegunungan dibutuhkan baju hangat. Kebanyakan bahan baku berasal dari hasil lahan dan kebun sendiri, tetapi beberapa yang berasal dari kain impor. Kain biru dan chintz diimpor dalam jumlah besar dari India Barat. Para penguasa biasanya membutuhkan banyak kain kemeja, beludru dan kain jenis lain untuk membuat jaket, celana pantalon dan pakaian lain, meniru gaya Eropa. Tak hanya meniru gaya Eropa, mereka juga kadang meniru busana para pendatang seperti para ulama. Bahan kain yang diperdagangkan, biasanya berkisar sutera, katun, lurik, atau beludru (Raffles, 2014:52). Penjelasan Thomas Stamford Raffles ini juga divisualisasikan melalui diorama dan mural yang terdapat dalam Museum Bahari.

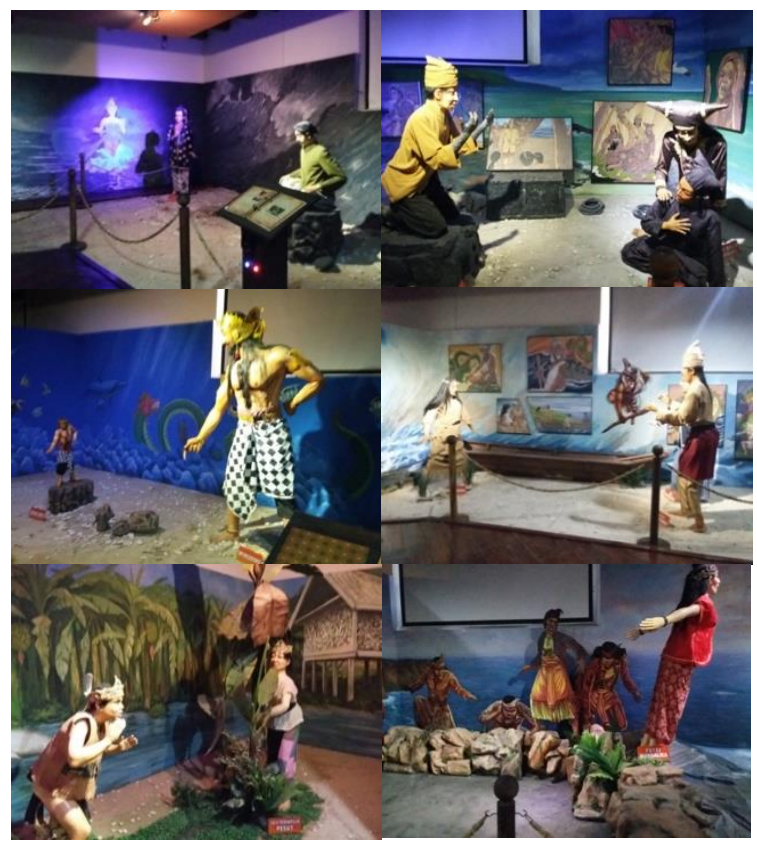

Gambar 3. Koleksi Diorama di Ruangan Legenda Laut Nusantara

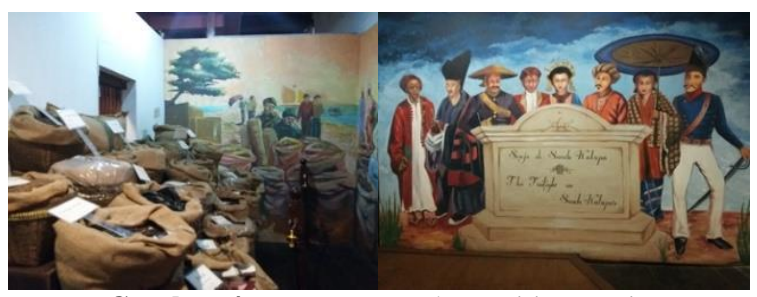

Gambar 4. Ruang Legenda Maritim Dunia

Pada artikel ilmiah pada jurnal Inosains berjudul Desain Karakteristik Busana Polisi Pariwisata Untuk Museum Bertema Bahari Melalui Pendekatan Fashion System Roland Barthes (Studi Kasus Museum Bahari Di Pulau Jawa), menjelaskan bahwa Museum Bahari yang berlokasi di Kawasan Kota Tua, Jakarta, memiliki beragam koleksi kebaharian Indonesia mulai dari kuno hingga modern. Bangunan ini berdiri sejak tahun 1652 yang di dalamnya beragam koleksi kebaharian Indonesia yang terletak di ruangan-ruangan tertentu. Untuk menyaksikan sejarah kebaharian Indonesia terdapat di lantai dua Museum Bahari ini yang ditata menggunakan diorama-diorama. Adapun Keempat ruangan terdiri dari Ruang Legenda Laut Internasional, Ruang Legenda Laut Nusantara, Ruang Legenda Maritim Dunia dan Ruang Legenda Navigator Dunia (Putri Anggraeni Widyastuti, 2015: 119-126). Jika mengacu pada sejarah perjuangan Sultan Ageng 
Tirtayasa ini maka, adapun ruangan yang menjadi acuan dalam perancangan buku cerita bergambar perjuangan Sultan Ageng Tirtayasa ini adalah pada koleksi diorama di Ruang Legenda Laut Nusantara dan Ruang Legenda Maritim Dunia.

\section{METODE PENELITIAN \\ Lokasi Studi}

Meskipun perancangan buku cerita bergambar sejarah perjuangan Sultan Ageng Tirtayasa ini mengambil daerah Banten sebagai lokasi pembuatan buku cerita bergambar sejarah, tapi untuk penelitian ini mengambil lokasi Studi di Museum Bahari di kawasan Kota Tua Jakarta. Alasan Museum Bahari ini dipilih adalah karena museum ini memiliki koleksi diorama yang bisa dijadikan sebuah referensi dalam menganalisis pakaian tokoh pada perancangan buku cerita bergambar sejarah perjuangan Sultan Ageng Tirtayasa.

\section{Analisis Data}

Meskipun objek penelitian ini adalah rancangan buku cerita bergambar sejarah perjuangan Sultan Ageng Tirtayasa dalam bentuk dua dimensi, tetapi yang akan dikaji adalah pakaian yang dikenakan oleh para tokoh dalam cerita ini. Oleh karena itu diperlukan analisa visual karakteristik pakaian tersebut. Dalam bukunya Visualisasi Iklan Indonesia Era 1950-1957 karya Didit Widiatmoko Soewardikoen, yang juga dikutip dalam jurnal Inosains yang berjudul Visualisasi Ergonomi Papan Informasi Koleksi Artefak karya Putri Anggraeni Widyastuti juga menjelaskan untuk menilai visual sebuah produk atau gambar iklan, imaji dapat ditelaah menurut beberapa aspek. Telaah asas sosial diperlukan untuk menentukan makna visual iklan dari analisis terhadap ilustrasi, penggambaran figur, stereotip ras, pakaian, dan pola wawasan. Rangkuman dari lima kategori ini menjadi pola visualisasi yang membentuk karakter visual iklan era itu (Soewardikoen, 2015:67; dikutip juga dalam Widyastuti, 2018: ). Karakter visual iklan era tersebut pun dapat digunakan untuk menganalisis visual karakteristik pakaian para tokoh pada perancangan buku bercerita sejarah perjuangan Sultan Ageng Tirtayasa. Dari hasil analisis visual karakteristik ini pun nantinya akan diketahui proses metafora apa yang digunakan dalam proses perancangan buku cerita bergambar sejarah perjuangan Sultan Ageng Tirtayasa.

\section{HASIL PENELITIAN DAN ANALISIS}

Mengingat penelitian ini berfokus pada analisa visual karakteristik pakaian tokoh-tokoh pada perancangan buku cerita bergambar sejarah perjuangan Sultan Ageng Tirtayasa, maka selanjutnya akan dilakukan penelusuran pada halaman pengenalan karakter buku ini yang terdiri dari Sultan Ageng Tirtayasa, kedua putranya
(Pangeran Purbaya dan Pangeran Gusti/Sultan Haji), Kompeni, VOC, dan Kapten Tack. Mengingat pula kejadian pertempuran antara Banten dan VOC diadakan tahun 1682, maka dilakukan penelusuran material atau kain yang dikenakan oleh para tokohtokoh tersebut. Seperti yang dijelaskan bahwa dengan makin berkembangnya transportasi yang mengakibatkan makin maju perdagangan dibidang tekstil kala itu, membuat beragam tekstil yang ada di Eropa atau Asia pun mulai berdatangan di Banten kala itu. Penggunaan kain pun tidak sembarangan digunakan oleh sembarang orang kala itu. Sebagai contoh untuk Sultan Ageng Tirtayasa mengenakan beskap dari bahan beludru berwarna hitam dan juga dihiasi dengan motif benang emas yang menandakan dirinya sebagai seorang raja seperti pada kerajaan di pulau Jawa pada umumnya, serta mengenakan topi kebanggaannya dan melilitkan kain batik. Sementara untuk kedua anaknya mungkin hanya menggunakan bahan drill atau katun yang juga tetap ada hiasan emas pada bagian luaran dan juga bagian pinggang untuk menandakan bahwa keduanya masih keturunan bangsawan. Mereka juga mengenakan tutup kepala serban yang mencirikan agama yang dianutnya kala itu. Sementara untuk karakter antagonis seperti Kompeni, tentara VOC dan Kapten Tack ini mengenakan pakaian tentara VOC pada masa itu. Warna biru merupakan ciri khas dari pakaian tentara Eropa kala itu lengkap dengan mengenakan kemeja dan dasi berumbai. Untuk luarannya mereka mengenakan rompi hitam senada dengan celana panjangnya, atau pun rompi berlengan Panjang biru lengkap dengan dan legging atau kaus kaki berwarna merah. Tokoh antagonis ini mengenakan penutup kaki yakni sepatu dan juga membawa senjata berupa pistol atau pun pedang. Yang membedakan tentara dengan kapten dalam hal ini adalah penggunaan tanda pada kedua bagian bahunya.

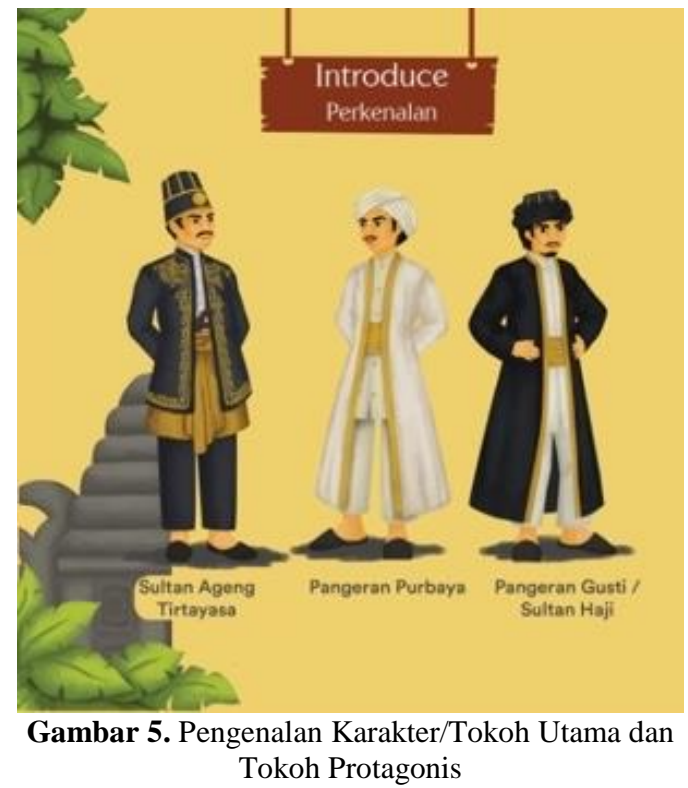




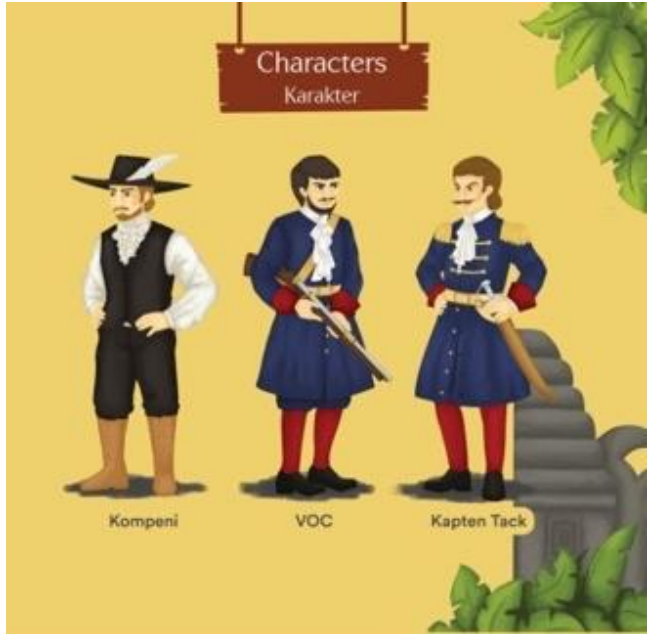

Gambar 6. Pengenalan Karakter/Tokoh Utama dan Tokoh Antagonis

Tabel 1. Hasil Analisa Telaah Sosial Visual Karakteristik Pakaian Tokoh Utama dan Protagonis Perancangan Buku Cerita Bergambar Sejarah Sultan Ageng Tirtayasa

\begin{tabular}{|c|c|c|}
\hline No & Telahar & Sultan Ageng Tirtayasa, Pangeran \\
\hline & Sosial Visual & $\begin{array}{l}\text { Purbaya, Pangeran Gusti/Sultan } \\
\text { Haji }\end{array}$ \\
\hline 1 & Ilustrasi & $\begin{array}{l}\text { Ilustrasi tokoh keluarga Sultan } \\
\text { Ageng Tirtayasa ini dibuat } \\
\text { menggunakan teknik digital } \\
\text { drawing dengan menggunakan } \\
\text { warna-warna khas nusantara } \\
\text { keturunan dari kerajaan Banten. }\end{array}$ \\
\hline 2 & $\begin{array}{l}\text { Penggambara } \\
\mathrm{n} \text { figur }\end{array}$ & $\begin{array}{l}\text { Tokoh keluarga Sultan Ageng } \\
\text { Tirtayasa berikut putra-putranya } \\
\text { Pangeran Purbaya dan Pangeran } \\
\text { Gusti merupakan keluarga } \\
\text { keturunan Kerajaan Banten, } \\
\text { sehingga penggambaran figurnya } \\
\text { seperti keturunan sultan yang } \\
\text { terlihat dari sikap dan pakaiannya } \\
\text { yang identik dengan } \\
\text { menggunakan kombinasi warna } \\
\text { emas sebagai warna-warna } \\
\text { bangsawan dengan warna puth } \\
\text { ataupun hitam. Perawakan wajah } \\
\text { nusantara identik dengan kumis }\end{array}$ \\
\hline 3 & Stereotip ras & $\begin{array}{l}\text { Keluarga Sultan Ageng Tirtayasa } \\
\text { berikut putra-putranya Pangeran } \\
\text { Purbaya dan Pangeran Gusti } \\
\text { menganut agama Islam dan juga } \\
\text { kebudayaan Jawa pada umumnya, } \\
\text { terlihat dari pakaian yang } \\
\text { digunakan mereka, seperti } \\
\text { beskap, kain batik, maupun baju } \\
\text { luaran panjang bermotif emas }\end{array}$ \\
\hline 4 & Pakaian & $\begin{array}{l}\text { Sultan Ageng Tirtayasa } \\
\text { mengenakan pakaian Sultan pada } \\
\text { umumnya yang ada di Pulau } \\
\text { Jawa, topi, kemeja dalaman, dan } \\
\text { juga tak lupa melilitkan kain batik } \\
\text { serta menggunakan celana. Ia dan } \\
\text { putranya mengenakan sandal } \\
\text { selop sebagai tanda seorang } \\
\text { bangsawan. Sementara untuk } \\
\text { kedua putranya dibedakan dari } \\
\text { warna yakni wana putih dan }\end{array}$ \\
\hline
\end{tabular}

\begin{tabular}{|l|l|l|}
\hline & & $\begin{array}{l}\text { hitam. Mereka berdua juga } \\
\text { mengenakan serbanyang berbeda } \\
\text { tapi tetap mencirikan agama yang } \\
\text { dianut oleh mereka }\end{array}$ \\
\hline 5 & Pola wawasan & $\begin{array}{l}\text { Tokoh Sultan Ageng Tirtayasa, } \\
\text { Pangeran Purbaya, Pangeran } \\
\text { Gusti/Sultan Haji memiliki pola } \\
\text { wawasan untuk mensejahterakan } \\
\text { masyarakat Kerajaan Banten dan } \\
\text { berusaha mengusir tokoh } \\
\text { Kompeni dan lain-lain yang } \\
\text { berusaha menguasai sumber daya } \\
\text { alam di Banten }\end{array}$ \\
\hline
\end{tabular}

Tabel 2. Hasil Analisa Telaah Sosial Visual Karakteristik Pakaian Tokoh Antagonis Perancangan Buku Cerita Bergambar Sejarah Sultan Ageng Tirtayasa

\begin{tabular}{|c|c|c|}
\hline No & $\begin{array}{l}\text { Telahan } \\
\text { Sosial Visual }\end{array}$ & Kompeni, VOC, dan Kapten Tack \\
\hline 1 & Ilustrasi & $\begin{array}{l}\text { Ilustrasi tokoh kompeni, VOC, } \\
\text { dan Kapten Tack juga } \\
\text { menggunakan teknik digital } \\
\text { drawing dengan menggunakan } \\
\text { warna-warna khas penjajah } \\
\text { tentara Eropa di era penjajahan } \\
\text { VOC }\end{array}$ \\
\hline 2 & $\begin{array}{l}\text { Penggambara } \\
\mathrm{n} \text { figure }\end{array}$ & $\begin{array}{l}\text { Yang membedakan tokoh } \\
\text { Kompeni, VOC, dan Kapten Tack } \\
\text { ini terlihat dari penggambaran } \\
\text { figure berwajah dan berkulit } \\
\text { Eropa, pakaian tentara Eropa pada } \\
\text { masa VOC, seperti kombinasi } \\
\text { warna putih-hitam, merah-biru- } \\
\text { putih-emas. Hanya saja dalam } \\
\text { pengenalan karakter ini tinggi dan } \\
\text { perawakan badan tokoh kompeni, } \\
\text { VOC, dan kapten Tack tidak lebih } \\
\text { besar dari tokoh keluarga Sultan } \\
\text { Ageng Tirtayasa. }\end{array}$ \\
\hline 3 & Stereotip ras & $\begin{array}{l}\text { Tokoh Kompeni, VOC dan } \\
\text { Kapten Tack memiliki figure } \\
\text { Eropa pada masa VOC yang } \\
\text { terlihat dari adanya brewok, dan } \\
\text { rambut panjang diikat, serta } \\
\text { kumis. Mereka juga mengenakan } \\
\text { sepatu yang berbeda dengan } \\
\text { tokoh keluarga Sultan Ageng } \\
\text { Tirtayasa. Pakaian yang } \\
\text { dikenakan khususnya berkemeja } \\
\text { lengkap dengan dasi berdraperi } \\
\text { yang menjadi ciri khas dari ketika } \\
\text { tokoh ini }\end{array}$ \\
\hline 4 & Pakaian & $\begin{array}{l}\text { Tokoh Kompeni, VOC, dan } \\
\text { Kapten Tack mengenakan } \\
\text { pakaian kemeja putih, berdasi } \\
\text { draperi rumbai-rumbai putih, } \\
\text { rompi hitam dan jas panjang } \\
\text { luaran berwarna biru donker khas } \\
\text { warna Eropa, serta kaus } \\
\text { kaki/legging warna merah. Yang } \\
\text { membedakan VOC dan Kapten } \\
\text { Tack terdapat pada senjata yang } \\
\text { dikenakan dan ada/tidaknya } \\
\text { penanda di kedua bahu mereka } \\
\text { berdua. Sedangkan Kompeni } \\
\text { mengenakan sepatu boots berbeda }\end{array}$ \\
\hline
\end{tabular}




\begin{tabular}{|l|l|l|}
\hline & & dengan VOC dan Kapten Tack. \\
\hline 5 & Pola wawasan & Tokoh Kompeni, VOC dan \\
& Kapten Tack ini memiliki pola \\
& wawasan untuk monopoli \\
& terhadap sumber daya alam \\
& sumber daya manusia nusantara \\
dengan strategi menguasai \\
kerajaan-kerajaan di Nusantara, \\
seperti Kerajaan Banten
\end{tabular}

Mengingat buku cerita bergambar sejarah perancangan Sultan Ageng Tirtayasa yang memiliki bahasa bilingual ini mempunyai ilustrasi yang ditujukan untuk anak-anak, maka pada proses perancangan tokoh karakter sejarah perjuangan Sultan Ageng Tirtayasa pun disesuaikan dengan dokumentasi pakaian kala itu. Maka setelah melakukan sebuah penelusuran terhadap pakaian tokoh-tokoh pada perancangan cerita bergambar sejarah perjuangan Sultan Ageng Tirtayasa ini di Museum Bahari yang di dalamnya memiliki koleksi diorama sehingga dapat dijadikan referensi untuk melihat memutuskan proses perancangan pakaian tokoh dalam cerita bergambar sejarah Sultan Ageng Tirtayasa ini mengambil proses metafora apa. Metafora sendiri menurut Andry Masri dalam bukunya Strategi Visual mengatakan metafora adalah peminjaman satu entitas yang lain, meminjam satu objek atau menggabungkan satu objek yang berbeda pada objek lain dengan tujuan memindahkan makna yang ada pada objek yang dipinjam dengan harapan makna tersebut dapat terbangun pada objek yang meminjam. Lakoff dan Johnson menyatakan bahwa metafora tidak hanya digunakan pada bidang bahasa dan linguistik saja, tetapi digunakan sebagai cara pikiran dalam berproses dan mengontruksi sesuatu (Masri, 2010:184-185).

Buku cerita bergambar sejarah Sultan Ageng Tirtayasa ini bisa dikatakan merupakan salah satu buku ilustrasi dokumentasi sesuai dengan sejarah tokoh utamanya. Maka saat merancang buku ini pun juga harus menyesuaikan dengan sejarah kala itu dan juga disesuaikan dengan target pasarnya yakni anakanak. Maka warna maupun ilustrasinya pun disesuaikan untuk anak-anak. Oleh karena itu metafora yang digunakan dalam perancangan buku cerita bergambar sejarah Sultan Ageng Tirtayasa ini menggunakan kombinasi metafora mimesis dan stilasi. Metafora mimesis sendiri merupakan peniruan seutuhnya dari objek yang dipinjam, dalam hal ini adalah pakaian tokoh-tokoh dalam perancangan buku cerita bergambar sejarah Sultan Ageng Tirtayasa dikontruksikan sama seperti dokumentasi pada masa VOC sekitar tahun 1600-an di Banten dalam bentuk visual dua dimensi.

Penggunaan metafora mimesis ini pun juga pernah digunakan pada sebuah kegiatan pengabdian kepada masyarakat PAUD tentang pelatihan keterampilan tangan menggunakan media kertas dengan tema pengenalan pakaian tradisional Jawa Barat di mana secara visual pun harus mendekati kebaya Sunda dan pangsi, yang merupakan pakaian tradisional Jawa Barat. Kegiatan pengabdian kepada masyarakat ini pun dituangkan dalam bentuk penelitian yang berjudul "A Study of the Process of Building and Creating Origami Product of Traditional Cloth West Java (Case Studi: Community Service in PAUD Anggrek 011)" pada jurnal IICACS di mana penelitian ini menjelaskan analisa proses membangun dan terbentuknya produk origami yang diperuntukkan bagi anak PAUD. Jurnal ini juga menjelaskan penggunaan metafora mimesis dipilih pada kegiatan ini karena metafora mimesis ini meniru seutuhnya dari objek yang dipinjam untuk menyampaikan makna yang jelas meski memiliki kekurangan kualitas visual yang sangat rendah. Tapi metafora mimesis ini efektif dalam pengenalan sebuah objek terhadap anak-anak. Mengingat usia anak-anak belajar mengingat objek dengan lebih baik lagi (Widyastuti, 2021:42-50).

Sementara metafora stilasi atau pengayaan, yang merupakan proses peniruan dari satu objek dengan cara melebih-lebihkan satu bagian dan mengurangi satu bagian yang lain, yang digunakan dalam perancangan buku cerita bergambar sejarah Sultan Ageng Tirtayasa ini digunakan dengan menyesuaikan target pasar buku ini. Tak heran dalam ilustrasinya pun sederhana dan mudah dilihat dengan kombinasi warna yang cocok untuk target pasar buku ini dengan menggunakan teknik digital dalam proses perancangannya.

\section{KESIMPULAN}

Dalam mengkaji visual karakteristik pakaian tokoh/karakter dalam perancangan buku cerita bergambar sejarah perjuangan Sultan Ageng Tirtayasa ini menggunakan telaahan sosial seperti halnya saat menganalisa sebuah iklan-iklan lawas. Hal ini dikarenakan bagaimana pun iklan-iklan cetak merupakan media dokumentasi kondisi suasana masyarakat kala itu. Begitu pula dengan buku cerita bergambar ini yang juga menceritakan sejarah perjuangan Sultan Ageng Tirtayasa. Pada buku cerita bergambar sejarah Sultan Ageng Tirtayasa ini terdiri dari tokoh utama (Sultan Ageng Tirtayasa), tokoh protagonis (Pangeran Purbaya dan Pangeran Gusti/ Sultan Haji, dan tokoh antagonis (Kompeni, VOC, dan Kapten Tack).

Dua tokoh yang berlawanan ini memiliki visual karakteristik pakaian yang berbeda. Seperti tokoh utama dan tokoh protagonis yang berasal dari Kerajaan Banten (nusantara) yang kala itu menganut agama Islam, maka pakaian yang dikenakan pun memiliki nuansa keislaman seperti pakaian luaran yang panjang dan juga serban. Tak hanya itu sebagai keturunan bangsawan/sultan, tokoh utama dan tokoh protagonis mengenakan kain batik yang dililit dan menggunakan warna emas atau kuning pada baju dasarnya berwarna putih atau hitam. Sehingga secara visual karakteristiknya memberikan kesan mewah dan klasik. Selain itu juga hal ini sesuai dengan 
pakaian para bangsawan yang dikenakan saat itu yang menggunakan bahan beludru sebagai bahan yang dikenakan bangsawan dengan benang emas.

Sedangkan untuk tokoh antagonis yang sudah pasti berasal dari musuh tokoh utama dan protagonis ini, VOC yang berasal dari Belanda pun mengenakan pakaian sesuai eranya sekitar tahun 1600 -an di mana pada saat itu pakaian tentaranya tidak bisa dikatakan simpel, tertutup meski sedang menjajah nusantara. Mereka mengenakan dasi berumbai yang menjadi ciri tentara kala itu. Tokoh antagonis ini juga menggunakan warna putih dan hitam serta kombinasi warna merah-biru-putih-emas. Yang membedakan tentara dengan kaptennya adalah adanya penanda di bahu berwarna emas berumbai-rumbai dan juga menggunakan pedang sebagai simbol kepemimpinannya. Berbeda dengan para tentara lain yang mengenakan pistol. Para tokoh antagonis ini juga mengenakan sepatu berbeda dengan tokoh utama dan antagonis yang mengenakan sepatu selop.

Dari hasil analisa visual karakteristik tokoh dalam perancangan buku cerita bergambar sejarah perjuangan Sultan Ageng Tirtayasa didapatkan adanya penggunaan kombinasi metafora mimesis dan stilasi. Kombinasi kedua ini untuk menghasilkan sebuah ilustrasi dalam buku yang merupakan sebuah dokumentasi dan suasana sejarah perjuangan Sultan Ageng Tirtayasa melawan VOC di Banten ketika ia berkuasa sekitar tahun 1600an. Maka dari itu dilihat apakah pakaian yang terdapat pada para tokoh buku cerita itu telah sesuai dengan penelusuran referensi terkait di Museum Bahari dari segi metafora mimesis. Sementara metafora stilasi pun digunakan untuk penyesuaian gaya ilustrasi pada perancangan buku cerita bergambar sejarah Sultan Ageng Tirtayasa terhadap target pasar anak-anak sehingga kombinasi warna, figur, maupun gaya gambarnya pun disesuaikan dengan anak-anak menggunakan teknik digital drawing.

\section{PENGAKUAN}

Terima kasih kepada Juan Ef Reyza yang memperbolehkan perancangan buku cerita bergambar Sultan Ageng Tirtayasa dengan judul Sultan Ageng Tirtayasa-Legend of Banten dijadikan objek penelitian ini.

\section{DAFTAR PUSTAKA}

Raffles, T. S. (2014). History of Java. Yogyakarta: Penerbit Narasi.

Ricklefs, M.C. (2008). Buku Sejarah Indonesia Modern 1200 - 2008. Terj. A History of Modern Indonesia Since c. 1200 Fouth Edition. Jakarta: PT Serambi Ilmu Semesta.

Soewardikoen, D. W. (2015). Visualisasi Iklan Indonesia Era 1950-1957. Yogyakarta: Calpulis.

Widyastuti, P. A. (2015). Desain Karakteristik Busana Polisi Pariwisata Untuk Museum Bertema Bahari Melalui Pendekatan Fashion System Roland Bartes (Studi Kasus: Museum Bahari di Pulau Jawa). Jurnal Inosains, 10 (2), 119-126.
Widyastuti, P. A. (2018). Visualisasi Ergonomi Papan Informasi Koleksi Artefak. Jurnal Inosains. Vol. 13. No 1.

Widyastuti, P. A., Huddiansyah. (2021). A Study of the Process of Building and Creating Origami Product of Traditional Cloth West Java (Case Studi: Community Service in PAUD Anggrek 011). IICACS, 1(1), 4250 . 